This is the peer reviewed version of the following article: [Hammerer, F., Ostadjoo, S., Friščić, T., and Auclair, K. (2019). Towards Controlling the Reactivity of Enzymes in Mechanochemistry: Inert Surfaces Protect $\beta$-glucosidase activity during ball milling. ChemSusChem, 2020, 13, 106-

110. https://doi.org/10.1002/cssc.201902752

\title{
Towards controlling the reactivity of enzymes in mechanochemistry: inert surfaces protect $\beta$-glucosidase activity during ball milling
}

\author{
Fabien Hammerer, ${ }^{[a]}$ Shaghayegh Ostadjoo, ${ }^{[a]}$ Tomislav Friščić*[a] and Karine Auclair*[a] \\ Dr. F. Hammerer, Dr. S. Ostadjoo, Dr. T. Friščić, Dr. K. Auclair \\ Chemistry Department, McGill University, 801 Sherbrooke St. W., Montreal (QC), H3A 0B8, Canada \\ E-mail: karine.auclair@mcgill.ca, tomislav.friscic@mcgill.ca
}

\begin{abstract}
We show how the activity of $\beta$-glucosidases, the enzymes responsible for the final step in the enzymatic conversion of cellulose to glucose, can be maintained and manipulated under mechanochemical conditions, either through an unexpected stabilization effect of inert surfaces, or by altering the enzymatic equilibrium in the absence of bulk solvent. While the reported results illustrate unique aspects of mechanoenzymatic reactions that are not observable in conventional aqueous solutions, they also represent the first reported strategies to enhance activity and favour either direction of the reaction under mechanochemical conditions.
\end{abstract}

Cellulose is the most abundant biopolymer on Earth ${ }^{[1]}$ and central to many strategies for developing renewable and sustainable alternatives to fossil resources for the production of fuels and chemicals. ${ }^{[2]}$ The deployment of lignocellulosic biomass as a renewable feedstock is hindered by its recalcitrant nature, including its poor solubility and low reactivity. ${ }^{\left[{ }^{[3}\right.}$ Additionally, cellulose in lignocellulosic material is intricately mixed with the biopolymers hemicellulose and lignin, ${ }^{[4]}$ impeding its accessibility and separation, and requiring the use of harsh and wasteful conditions for biomass saccharification. ${ }^{[5]}$ Whereas cellulosic materials in nature are degraded by mixtures of cellulase enzymes (exoglucanases, endoglucanases, $\beta$ glucosidases, etc.) secreted by microorganisms, the use of such enzymes in cellulose-based industries requires initial harsh physical and chemical pre-treatment of the cellulosic material, e.g. with sulphuric acid. ${ }^{[6]}$ Furthermore, since $\beta$-glucosidases (BGs) - enzymes responsible for cleavage of the $\beta$-(1-4)-glucose dimer (cellobiose) into glucose (Fig. 1) - are often limiting in cellulases mixtures, incomplete depolymerization is a common problem. ${ }^{[7]}$

Recently, we reported that cellulases can catalyse the efficient hydrolysis of both microcrystalline cellulose (MCC) and raw lignocellulosic biomass directly into glucose without chemical pre-treatment. ${ }^{[8]}$ This was made possible by a mechanochemistry-based process termed reactive aging (RAging), which consists of alternating cycles of brief mechanochemical activation by milling in the presence of a minute amount of water, followed by aging ${ }^{\left[{ }^{[]}\right.}$of the resulting moist powder at a mild temperature $\left(45-55^{\circ} \mathrm{C}\right)$. The volume of water used in RAging is significantly lower than in conventional solutions or slurries, with the liquid-to-solid ratio $(\eta)^{[10]}$ below $1 \mu \mathrm{L} / \mathrm{mg}$, consistent with liquid-assisted grinding (LAG) mechanochemical conditions. ${ }^{[11]}$ By using near-stoichiometric amounts of water, this solvent-free environment better mimics the conditions for which cellulases have been naturally selected for, achieving a fast, efficient and clean hydrolysis of crystalline cellulose or native biomass. Furthermore, RAging avoids the energy consumption associated with continuous heating and stirring of large volumes of aqueous suspensions used in conventional processes, and affords the highest glucose concentration reported to date for an enzyme-based cellulose depolymerization process.

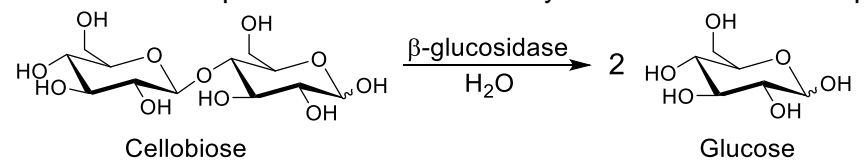

Figure 1. Reaction catalysed by $\beta$-glucosidases.

The ability to use enzymes under mechanochemical conditions is a recent development, and only a handful of mechanoenzymatic reactions have been reported so far. ${ }^{[12]}$ Whereas mechanoenzymology was found to rival or even surpass classical biocatalysis, the factors involved remain almost completely unexplored. Here, we investigate the behaviour of commercial BGs from Aspergillus niger under solvent-free mechanochemical conditions and demonstrate the ability to manipulate the enzymatic reaction equilibrium, as well as an unexpected role of chemically inert surfaces in preserving BG 
This is the peer reviewed version of the following article: [Hammerer, F., Ostadjoo, S., Friščić, T., and Auclair, K. (2019). Towards Controlling the Reactivity of Enzymes in Mechanochemistry: Inert Surfaces Protect $\beta$-glucosidase activity during ball milling. ChemSusChem, 2020, 13, 106-

110. https://doi.org/10.1002/cssc.201902752

activity under such conditions. To the best of our knowledge, our results represent the first demonstration of methods to manipulate the reactivity of an enzyme in the absence of organic or aqueous bulk solvent.

The commercial lyophilized BG powder used in this study was found to contain ca. $34 \%(\mathrm{w} / \mathrm{w}$ ) of various proteins (Bradford assay and Fig. S1), and displayed BG activity, but no endoglucanase or exoglucanase activity. All mechanochemical reactions presented below were conducted in $15 \mathrm{~mL}$ volume stainless steel jars, containing two stainless steel balls of $7 \mathrm{~mm}$ diameter (1.37 g) each. The value of $\eta$ was kept below $1 \mu \mathrm{L} / \mathrm{mg}$, i.e. within LAG conditions, enabling solubility-independent reactions. ${ }^{\left[{ }^{10]}\right.}$ Unlike our previously reported solvent-free reactions of cellulose catalyzed by the cellulase enzymes mixtures (including BG and other glycosylhydrolases), which proceed to form glucose in high yield, the activity of BG alone on pure cellobiose was very slow (Fig. S2). For example, the total yield of glucose after milling for 30 minutes at a frequency of $30 \mathrm{~Hz}$ and $\eta=0.48$ $\mu \mathrm{L} / \mathrm{mg}$ was below $5 \%$, and did not reach $10 \%$ even after subsequent aging for 3 days at $55^{\circ} \mathrm{C}$ (Fig. 2). This is significantly lower than a previously reported cellulose-to-glucose yield of $\sim 50 \%$ with the $T$. longibrachiatum cellulases mixture under similar conditions. ${ }^{[8]}$ This was surprising since, in the cellulases mixture, $B G$ is the enzyme responsible for producing the majority of glucose. When a freshly milled mixture of BG and cellobiose was diluted in water, no additional conversion was observed, suggesting permanent deactivation of BG by milling (Fig. S3). ${ }^{[13]}$ In comparison, performing the same reaction in solution, and without any prior milling, led to almost complete cellobiose consumption within 1 hour (Fig. S4). Drawing on the previous successful use of cellulase mixtures in cellulose hydrolysis, it appears that under mechanochemical conditions BG is more active in the presence of complex cellulosic material than with cellobiose only.

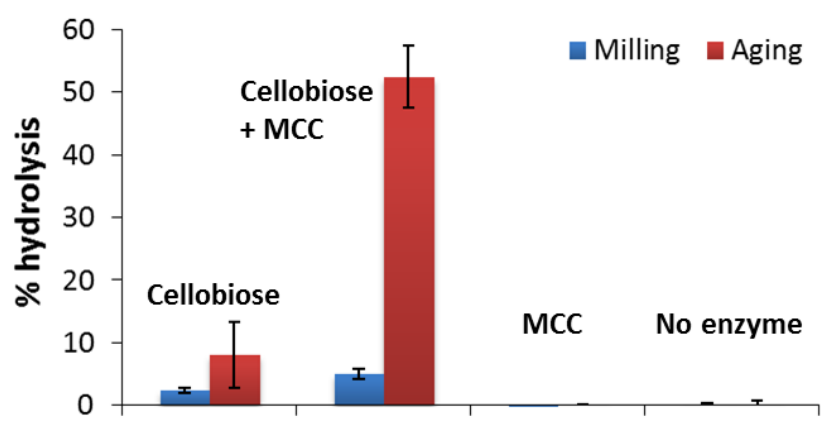

Figure 2. Enzymatic conversion of cellobiose to glucose using LAG. Reactions contained $400 \mathrm{mg}$ of either cellobiose, or MCC, or a mixture of both (1:1 $\mathrm{w} / \mathrm{w})$, combined with $20 \mathrm{mg}$ of enzyme preparation, and $200 \mu \mathrm{L}$ water $(\eta=0.48 \mu \mathrm{L} / \mathrm{mg})$. The control reaction without enzyme was conducted on the $1: 1$ mixture of cellobiose and MCC. Mixtures were milled for 30 minutes at $30 \mathrm{~Hz}$, and then aged for three days at $55^{\circ} \mathrm{C}$. Error bars are standard deviations with $\mathrm{n}=3$ for each point.

To verify this hypothesis, the mechanoenzymatic reactions were repeated, but with half of the cellobiose by weight (w/w) replaced with MCC, while keeping all other parameters unchanged. Under these conditions, the yield of the BG-catalyzed reaction increased from $<8 \%$ to $>50 \%$ (Fig. 2). The reaction mixtures continued to undergo catalytic hydrolysis not only during subsequent aging but also after dilution of the milled material in water (Fig. S3). A control experiment conducted without enzyme revealed no conversion to glucose, confirming that the generation of glucose was due to enzymatic activity. Similarly, completely replacing the substrate with MCC led to no glucose production, consistent with the inability of BG to directly depolymerize cellulose. The same activity was obtained by replacing water as the LAG additive with a sodium acetate buffer ( $50 \mathrm{mM}, \mathrm{pH} 5$; Fig. S5). In contrast, the addition of MCC to enzymatic reactions in solution did not improve the outcome, even when the enzyme and MCC were incubated together prior to substrate addition (Fig. S4). This was expected based on reports that fungal BGs usually exhibit only weak intrinsic affinity for cellulose due to their lack of a specific carbohydrate binding domain. ${ }^{[14]}$ Taken together, these results show that the presence of non-reactive biopolymer MCC helps preserve BG activity under mechanochemical conditions.

Since our data suggested that milling in the absence of MCC may induce BG denaturation, we next probed the effect of milling frequency on BG activity (Fig. S6). Regardless of the frequency used, milling cellobiose and BG in the absence of MCC $(\eta=0.48 \mu \mathrm{L} / \mathrm{mg}$ ) provided only poor conversion to glucose $(<5 \%)$. The yield was however significantly improved (up to $15 \%)$, if milling was conducted in the presence of MCC additive. When milling without MCC was followed by aging for 3 days, lower milling frequencies produced a higher conversion to glucose, whereas in the presence of MCC all frequencies gave comparable yields after aging, reaching $54 \%( \pm 6 \%)$. This corresponds to a final glucose concentration of ca. $3 \mathrm{M}$, which would be difficult to achieve under conventional aqueous conditions since BGs are typically inhibited by glucose at low to high 
This is the peer reviewed version of the following article: [Hammerer, F., Ostadjoo, S., Friščić, T., and Auclair, K. (2019). Towards Controlling the Reactivity of Enzymes in Mechanochemistry: Inert Surfaces Protect $\beta$-glucosidase activity during ball milling. ChemSusChem, 2020, 13, 106-

110. https://doi.org/10.1002/cssc. 201902752

millimolar concentrations. ${ }^{[15]}$ These observations highlight the use of inert additives as a more effective strategy to control mechanoenzymatic activity compared to reducing the milling frequency.

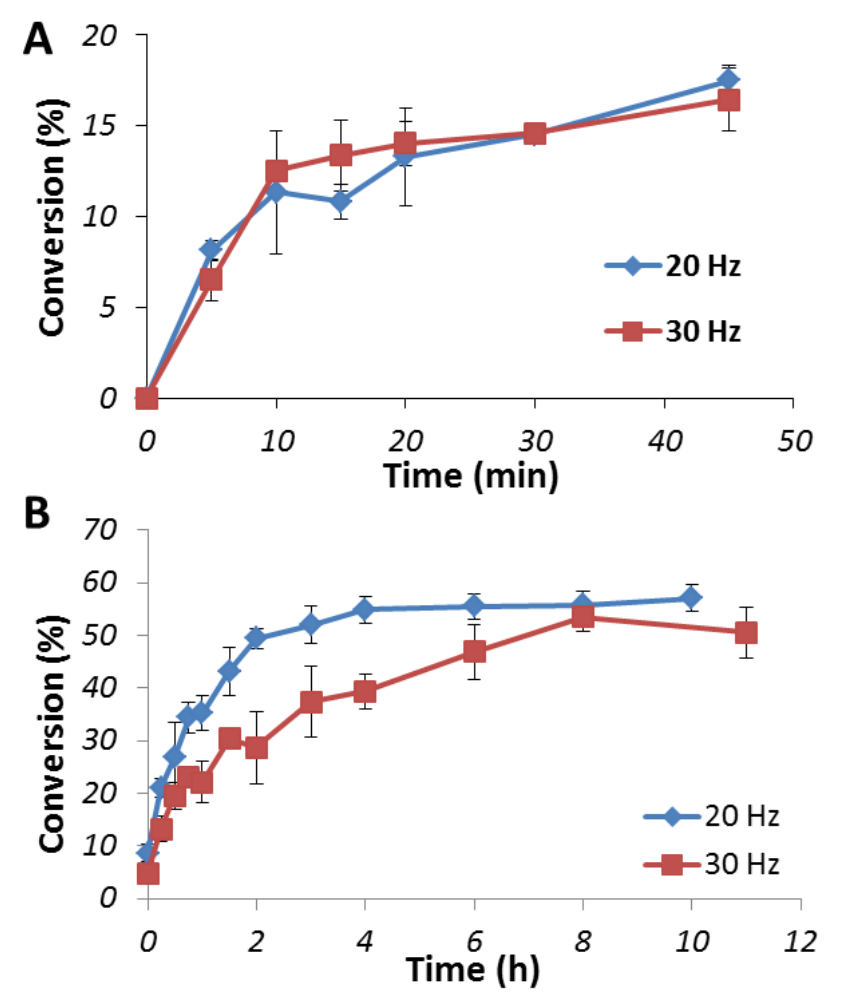

Figure 3. Kinetics of solvent-free BG-catalyzed cellobiose hydrolysis in the presence of MCC. Reactions contained 400 mg of MCC and cellobiose (1:1 w/w), combined with $20 \mathrm{mg}$ of enzyme preparation, and 200 or $400 \mu \mathrm{L}$ water $(\eta=0.48$ or $0.95 \mu \mathrm{L} / \mathrm{mg}$; A and B respectively). A) Milling only (20 Hz or 30 $\mathrm{Hz}$ ) monitored over time $(\eta=0.95 \mu \mathrm{L} / \mathrm{mg}), \mathrm{B})$ Aging at $55^{\circ} \mathrm{C}$ after milling for $15 \mathrm{~min}$ at 20 or $30 \mathrm{~Hz}$ monitored over time $(\eta=0.48 \mu \mathrm{L} / \mathrm{mg})$. Error bars are standard deviations with $\mathrm{n}=3$ for each point.

Solid-state differential scanning calorimetry (DSC) was used to further confirm the increased tolerance of BG to milling conferred by the presence of MCC. Analysis of milled BG reaction mixtures clearly demonstrates that milling without MCC leads to $B G$ denaturation, whereas a clear enzyme melting point $\left(T_{m} \text { expected at } 210-215^{\circ} \mathrm{C}\right)^{[16]}$ is observed after milling a reaction mixture containing MCC (Fig. S7). These observations are consistent with the interesting possibility that the MCC additive may provide a means to stabilize $B G$ during ball milling.

We also examined the kinetic profile of BG under various conditions, all lacking bulk water (Fig. 3). In the presence of MCC, and at milling frequencies of $20 \mathrm{~Hz}$ or $30 \mathrm{~Hz}(\eta=0.95 \mu \mathrm{L} / \mathrm{mg})$ without aging, the BG-catalyzed hydrolysis of cellobiose displayed typical hyperbolic behaviour, with an initial rate of hydrolysis $(10 \mu \mathrm{mol} / \mathrm{min})$ comparable to that of BG in solution (Fig. S3). Reactions at different milling frequencies ( 15 minutes at $20 \mathrm{~Hz}$ or $30 \mathrm{~Hz}$ ) gave comparable yields. 
This is the peer reviewed version of the following article: [Hammerer, F., Ostadjoo, S., Friščić, T., and Auclair, K. (2019). Towards Controlling the Reactivity of Enzymes in Mechanochemistry: Inert Surfaces Protect $\beta$-glucosidase activity during ball milling. ChemSusChem, 2020, 13, 106-

110. https://doi.org/10.1002/cssc.201902752

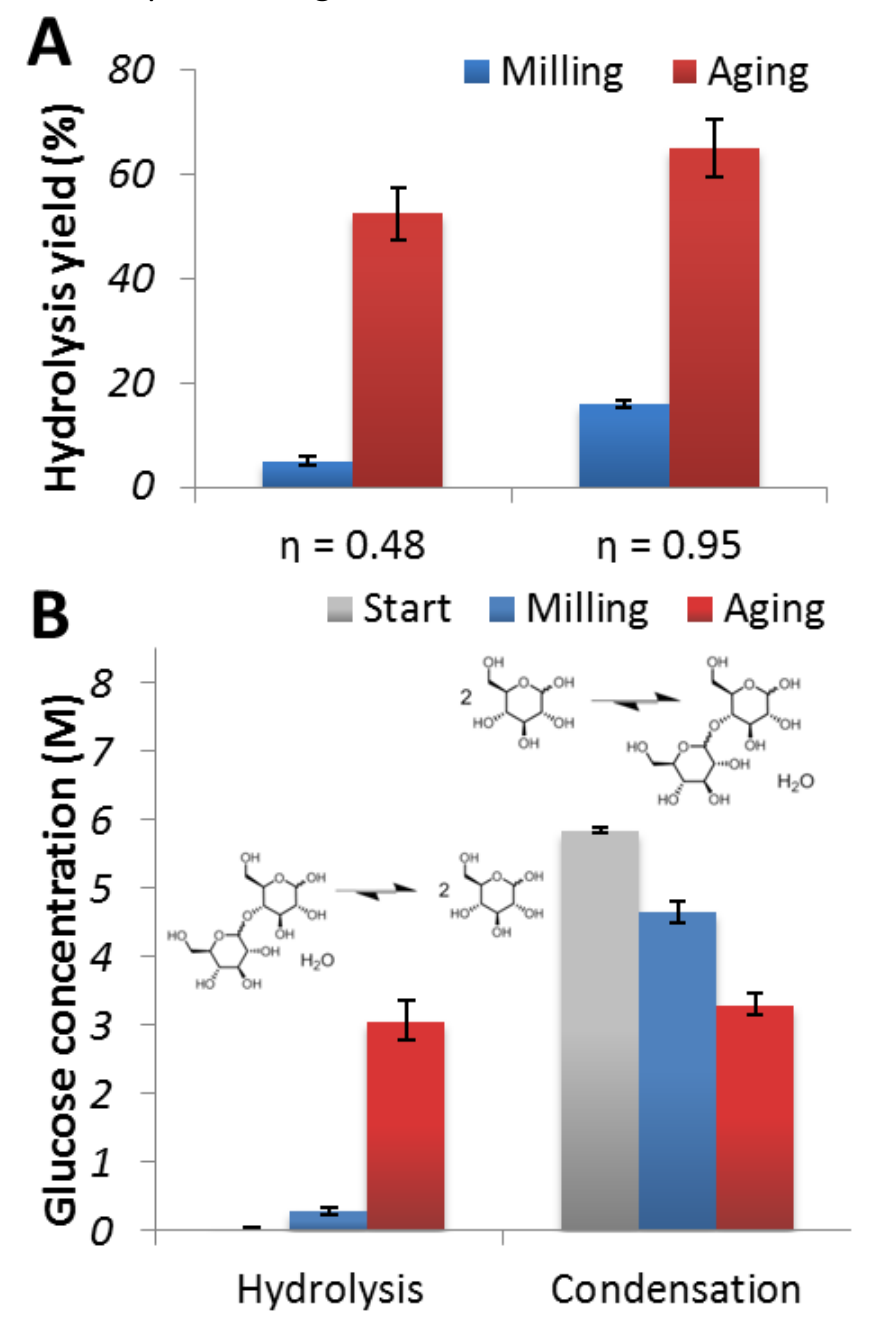

Figure 4. BG-catalyzed cellobiose hydrolysis or glucose condensation. A) Hydrolysis yield of cellobiose at $\eta=0.48$ or $0.95 \mu \mathrm{L} / \mathrm{mg}$. B) Hydrolysis and condensation comparison at $\eta=0.48 \mu \mathrm{L} / \mathrm{mg}$. All reactions contained $200 \mathrm{mg}$ cellobiose or $211 \mathrm{mg}$ glucose, $200 \mathrm{mg} \mathrm{MCC}, 20 \mathrm{mg}$ commercial BG powder, and 200 or $400 \mu \mathrm{L}$ water. They were milled at $30 \mathrm{~Hz}$ for $30 \mathrm{~min}$ then aged for 3 days at $55^{\circ} \mathrm{C}$. Error bars are standard deviations with $\mathrm{n}=3$ for each point.

Next, we studied the behaviour of BG under RAging conditions (Fig. S8), i.e. multiple cycles of milling (5 min at r.t., $\eta=0.95$ $\mu \mathrm{L} / \mathrm{mg}$ ) followed by aging $\left(55 \mathrm{~min}\right.$ at $\left.55^{\circ} \mathrm{C}\right)$. The yield of glucose reached $70 \%$ after only $2-3$ RAging cycles. Unexpectedly, however, we found that the amount of water may be a limiting factor during aging since reactions at $\eta=0.95 \mu \mathrm{L} / \mathrm{mg}$ led to noticeably higher yields (65\%) than those conducted at $\eta=0.48 \mu \mathrm{L} / \mathrm{mg}(55 \%$, Fig. 4A). We suspected that the observed effect of water content on reactivity might be linked to reaching an equilibrium between the product and substrate. Indeed, BGs are also known to catalyse the reverse process, i.e. the condensation of glucose into di- or oligosaccharides in concentrated solutions. ${ }^{[17]}$ We explored this possibility by examining the capacity of BG to promote glucose condensation under LAG conditions. After aging at $\eta=0.48 \mu \mathrm{L} / \mathrm{mg}$, we obtained matching final glucose concentrations (Fig 4B) starting either from glucose or cellobiose, corresponding to roughly $41 \pm 4 \%$ condensation yield (assuming only dimer formation), or $53 \pm 5 \%$ hydrolysis yield (leaving $47 \%$ unreacted cellobiose). To the best of our knowledge, although equilibria have been reported for chemical reactions under milling ${ }^{[18]}$ this is the first demonstration of an enzymatic reaction equilibrium under mechanochemical conditions, raising the possibility of controlling the direction of mechanoenzymatic reactions by varying the amount of water used, a synthetic opportunity that is not accessible in solvent-rich environments typically used with enzymes.

Next, we explored whether other materials besides MCC could serve to enhance BG activity under mechanochemical conditions. Thus, a variety of readily available biopolymers were screened, including non-functionalized or sulphonated cellulose nanocrystals (CNCs), xylans from different sources, lignin and chitin. All gave comparable results to MCC, with lignin 
This is the peer reviewed version of the following article: [Hammerer, F., Ostadjoo, S., Friščić, T., and Auclair, K. (2019). Towards Controlling the Reactivity of Enzymes in Mechanochemistry: Inert Surfaces Protect $\beta$-glucosidase activity during ball milling. ChemSusChem, 2020, 13, 106-

110. https://doi.org/10.1002/cssc.201902752

being the least effective (Fig. 5). As lignocellulosic biomass consists mainly of cellulose, hemicellulose (xylans), and lignin, these observations are consistent with the high BG activity observed during biomass depolymerization by the cellulases mixture under RAging conditions. ${ }^{[8]}$ Interestingly, synthetic polymers like polystyrene (PS), polymethylmethacrylate (PMMA), and polyethylene glycol 4000 (PEG-4000) were also found to increase BG stability upon milling. While the first two are rigid polymers poorly soluble in water, the last one is largely water soluble and more flexible.

Upon milling, the reaction mixture containing the solid PEG-4000 turned into a fluid suspension, as opposed to pasty solids obtained with other polymeric additives. A similar liquid phase was obtained when using corncob xylan, which is soluble in water, implying that soluble and insoluble polymers can serve as additives to protect BG activity. The use of inorganic oxide additives, specifically $\mathrm{SiO}_{2}, \mathrm{ZnO}$ and $\mathrm{CeO}_{2}$ provided mixed results, with ceria-containing reactions behaving similar to those containing organic polymers, while significantly poorer BG activity was observed with $\mathrm{ZnO}$ or $\mathrm{SiO}_{2}$. The Mohs hardness ${ }^{[19]}$ of the three oxides is similar, and it is not yet clear what the cause of the observed differences is.

The use of polymers in ball milling, a technique called polymer-assisted grinding (POLAG), has been reported to promote organic reactions ${ }^{[20]}$ and formation of co-crystals by providing a controlled micro-environment. ${ }^{[21]}$ Moreover, both silica and lignin have been used as additives to enhance the Strecker reaction and the synthesis of $\alpha$-aminonitriles under LAG conditions. ${ }^{[22]}$ The present report, however, is the first time that such a reaction-enhancing effect is reported for enzymes. It is possible that both micro- (e.g. polarity, hydrophobicity, chemical functionalization) and macroscopic parameters (e.g. abrasiveness, elasticity) have an influence on enzyme stability and efficacy. So far, we have not been able to correlate the effectiveness of the additive in protecting BG activity to a particular property (Table S1). The additives reported here to enhance the tolerance of BG to milling range from elastic to brittle, and also cover a wide range of density, thermal capacity, hydrophobicity, and aqueous solubility values. Nevertheless, as with enzymes in solution, the additives are likely stabilizing the folded proteins by providing a milieu that favors hydrophobic residues to be buried at the core of the protein and prevents aggregation. ${ }^{[13]}$

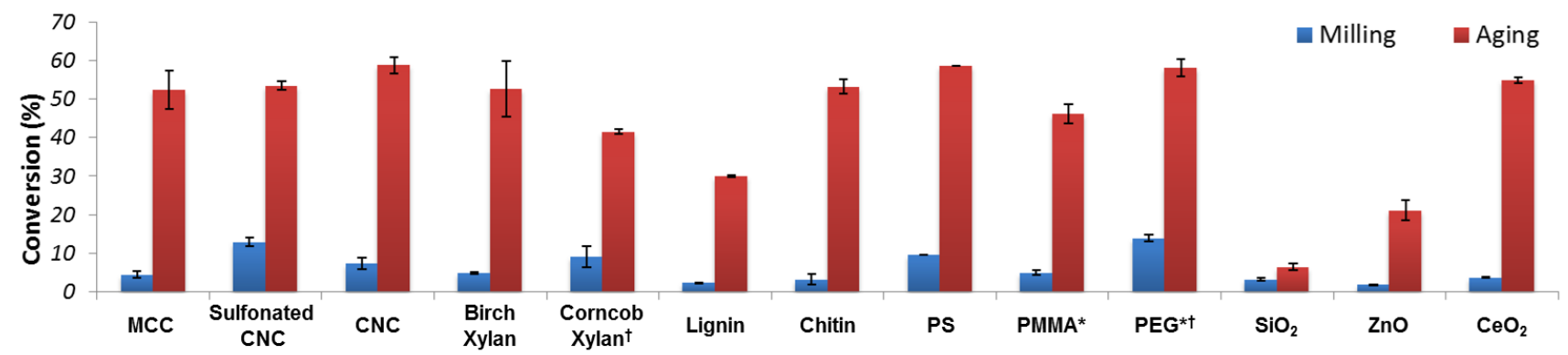

Figure 5. Screening polymers and solids as additives for their ability to protect BG. The reactions contained $200 \mathrm{mg}$ cellobiose, $200 \mathrm{mg}$ additive, $20 \mathrm{mg} \mathrm{BG}$ commercial preparation, $200 \mu \mathrm{L}$ water $(\eta=0.48 \mu \mathrm{L} / \mathrm{mg})$ and were milled for $30 \mathrm{~min}$ at $30 \mathrm{~Hz}$ before aging for 3 days at $55^{\circ} \mathrm{C}$. MCC: microcrystalline cellulose; CNC: cellulose nanocrystals; PS: polystyrene; PMMA: polymethylmethacrylate; PEG: polyethylene glycol of average MW 4000. Error bars are standard deviations with $n=3$ for each point. * Only $100 \mathrm{mg}$ of PEG used $(\eta=0.63 \mu \mathrm{L} / \mathrm{mg})$. 'Water soluble polymer.

In summary, mechanoenzymatic reactions are a very recent, emergent area at the interface of enzymology and solidstate chemistry, providing a highly unexplored approach to conducting enzyme catalysis. The presented results provide the first insight into ways through which enzyme reactivity under mechanochemically-activated conditions can be improved or even controlled. Specifically, we have demonstrated that the addition of chemically inert additives can be used to preserve the reactivity of $B G$ during ball milling or RAging reactions, affording a considerable yield enhancement. The wide variety of protective materials already identified infers that this strategy could be extended to other enzymes, and allow the development of new mechanoenzymatic reactions. In addition, we have also shown that BG activity in the absence of bulk solvent can be manipulated by using water content to control the enzymatic reaction equilibrium, with higher, yet still minute amounts favoring cellobiose cleavage, and lower amounts leading to dimer synthesis. Such an effect cannot be achieved in dilute solution conditions employed in conventional enzymology due to the abundance of solvent water, providing a clear and rational demonstration of new reaction design opportunities offered by a solvent-less reaction environment.

\section{Experimental Section}

Experimental details and procedures are available online in the Electronic Supplementary Information. 
This is the peer reviewed version of the following article: [Hammerer, F., Ostadjoo, S., Friščić, T., and Auclair, K. (2019). Towards Controlling the Reactivity of Enzymes in Mechanochemistry: Inert Surfaces Protect $\beta$-glucosidase activity during ball milling. ChemSusChem, 2020, 13, 106-

110. https://doi.org/10.1002/cssc.201902752

Acknowledgements

We acknowledge financial support from NSERC I2I, Canada Foundation for Innovation, and NSERC E. W. R. Steacie Memorial Fellowship (SMFSU 507347-17). Prof. A. H. Moores and B. G. Fiss, McGill University, are thanked for providing sulphonated CNC samples.

[1] John Wiley \& Sons Inc, Ed. , Kirk-Othmer Encyclopedia of Chemical Technology, John Wiley \& Sons, Inc., Hoboken, NJ, USA, 2000.

[2] a) Y. Sun, J. Cheng, Bioresour. Technol. 2002, 83, 1-11. b) J. J. Bozell, G. R. Petersen, Green Chem. 2010, 12, 539-554. c) (1) I. Delidovich, K. Leonhard, R. Palkovits, Energy Environ. Sci. 2014, 7, 2803-2830. d) Q. Xia, Z. Chen, Y. Shao, X. Gong, H. Wang, X. Liu, S. F. Parker, X. Han, S. Yang, Y. Wang, Nat. Commun. 2016, 7, 11162. e) J. Murray, D. King, Nature 2012, 481, 433-435. f) F. Cherubini, Energy Convers. Manag. 2010, 51, 1412-1421.

[3] a) M. C. McCann, N. C. Carpita, J. Exp. Bot. 2015, 66, 4109-4118. b) B. S. Donohoe, M. G. Resch, Curr. Opin. Chem. Biol. 2015, 29, 100107.

[4] C. P. Kubicek, E. M. Kubicek, Curr. Opin. Chem. Biol. 2016, 35, 51-57.

[5] a) A. Fukuoka, P. L. Dhepe, Angew. Chemie Int. Ed. 2006, 45, 5161-5163. b) S. Suganuma, K. Nakajima, M. Kitano, D. Yamaguchi, H. Kato, S. Hayashi, M. Hara, J. Am. Chem. Soc. 2008, 130, 12787-12793. c) T. Liebert, Cellulose Solvents - Remarkable History, Bright Future; 2010; pp 3-54. d) N. Sun, H. Rodríguez, M. Rahman, R. D. Rogers, Chem. Commun. 2011, 47, 1405-1421.

[6] a) R. Ravindran, A. K. Jaiswal, Bioresour. Technol. 2016, 199, 92-102. b) S. M. Bhatt, S. M.; Shilpa. Biofuels 2015, 5, 633-649. c) H. B. Klinke, AH. B. Thomsen, B. K. Ahring, Appl. Microbiol. Biotechnol. 2004, 66, 10-26.

[7] a) S. N. Olsen, K. Borch, N. Cruys-Bagger, P. Westh, Appl. Biochem. Biotechnol. 2014, 174, 146-155. b) J. B. Kristensen, C. Felby, H. Jørgensen, Biotechnol. Biofuels 2009, 2, 1-10. c) S. Kuusk, P. Väljamäe, Biotechnol. Biofuels 2017, $10,7$.

F. Hammerer, L. Loots, J.-L. Do, J. P. D. Therien, C. W. Nickels, T. Friščić, K. Auclair, Angew. Chemie Int. Ed. 2018, 57, 2621-2624.

[9] a) M. J. Cliffe, C. Mottillo, R. S. Stein, D.-K. Bučar, T. Friščić, Chem. Sci. 2012, 3, 2495. b) S. Kaabel, R. S. Stein, M. Fomitšenko, I. Järving, T. Friščić, R. Aav, Angew. Chemie - Int. Ed. 2019, 58, 6230-6234.

[10] T. Friščić, S. L. Childs, S. A. A. Rizvi, W. Jones, CrystEngComm 2009, 11, 418-426.

[11] a) S. L. James, C. J. Adams, C. Bolm, D. Braga, P. Collier, T. Friscic, F. Grepioni, K. D. M. Harris, G. Hyett, W. Jones, et al., Chem. Soc. Rev. 2012, 41, 413-447. b) J. L. Do, T. Friščić, Synlett 2017, 28, 2066-2092.

[12] a) J. G. Hernández, M. Frings, C. Bolm, ChemCatChem 2016, 8, 1769-1772. b) M. Pérez-Venegas, G. Reyes-Rangel, A. Neri, J. Escalante, E. Juaristi, Beilstein J. Org. Chem. 2017, 13, 1728-1734. c) K. J. Ardila-Fierro, D. E. Crawford, A. Körner, S. L. James, C. Bolm, J. G. Hernández, Green Chem. 2018, 20, 1262-1269. d) C. Bolm, J. G. Hernández, ChemSusChem 2018, 11, 1410-1420. e) J. P. D. Therien, F. Hammerer, T. Friščić, K. Auclair, ChemSusChem 2019, 12, 3481-3490.

[13] a) D. Kishore, S. Kundu, A. M. Kayastha, PLoS One 2012, 7, e50380. b) J. L. England, G. Haran, Annu. Rev. Phys. Chem. 2011, 62, 257277. c) E. R. McCarney, J. E. Kohn, K. W. Plaxco, Crit. Rev. Biochem. Mol. Biol. 2005, 40, 181-189. d) R. Singh, M. I. Hassan, A. Islam, F. Ahmad, PLoS One 2015, 10, e0128740. e) J. Roche, J. A. Caro, D. R. Noberto, P. Barthe, C. Roumestand, J. L. Schlessman, A. E. Garcia, B. Garcia-Moreno E., C. A. Royer, Proc. Natl. Acad. Sci. 2012, 109, 6945-6950.

[14] M. A. Lima, M. Oliveira-Neto, M. A. S. Kadowaki, F. R. Rosseto, E. T. Prates, F. M. Squina, A. F. P. Leme, M. S. Skaf, I. Polikarpov, J. Biol. Chem. 2013, 288, 32991-3005.

[15] a) W. Saibi, A. Gargouri, Carbohydr. Res. 2011, 346, 1848-1854. b) M. Chauve, H. Mathis, D. Huc, D. Casanave, F. Monot, N. Ferreira, Biotechnol. Biofuels 2010, 3, 3. c) R. F. H. Dekker, Biotechnol. Bioeng. 1986, 28, 1438-1442.

[16] a) M. A. Mohammad, I. M. Grimsey, R. T. Forbes, J. Pharm. Biomed. Anal. 2015, 114, 176-183. b) M. A. Mohammad, I. M. Grimsey, R.T. 
This is the peer reviewed version of the following article: [Hammerer, F., Ostadjoo, S., Friščić, T., and Auclair, K. (2019). Towards Controlling the Reactivity of Enzymes in Mechanochemistry: Inert Surfaces Protect $\beta$-glucosidase activity during ball milling. ChemSusChem, 2020, 13, 106-

110. https://doi.org/10.1002/cssc.201902752

Forbes, I. S. Blagbrough, B. R. Conway, Colloids Surfaces B Biointerfaces 2016, 146, 700-706.

[17] a) A. S. da Silva, J. F. Molina, R. S. S. Teixeira, L. G. Valdivieso Gelves, E. P. S. Bon, V. S. Ferreira-Leitão, Biotechnol. Lett. 2017, 39, 17171723. b) M. V. Semenova, O. N. Okunev, A. V. Gusakov, A. P. Sinitsyn, Open Glycosci. 2009, 2, $20-24$.

[18] a) J. G. Hernández, N. A. J. Macdonald, C. Mottillo, I. S. Butler, T. Friščić, Green Chem. 2014, 16, 1087-1092. b) (1) A. M. Belenguer, T. Friščić, G. M. Day, J. K.M. Sanders, Chem. Sci. 2011, 2, 696-700.

[19] D. Tabor, Proc. Phys. Soc. Sect. B 1954, 67, 249-257.

[20] a) A. Mascitti, M. Lupacchini, R. Guerra, I. Taydakov, L. Tonucci, N. d'Alessandro, F. Lamaty, J. Martinez, E. Colacino, Beilstein J. Org. Chem. 2017, 13, 19-25. b) V. Declerck, E. Colacino, X. Bantreil, J. Martinez, F. Lamaty, Chem. Commun. 2012, 48, 11778-11780. c) L. Konnert, M. Dimassi, L. Gonnet, F. Lamaty, J. Martinez, E. Colacino, RSC Adv. 2016, 6, 36978-36986.

[21] a) D. Hasa, E. Carlino, W. Jones, Cryst. Growth Des. 2016, 16, 1772-1779. b) D. Hasa, G. Schneider Rauber, D. Voinovich, W. Jones, Angew. Chemie Int. Ed. 2015, 54, 7371-7375.

[22] a) J. G. Hernández, M. Turberg, I. Schiffers, C. Bolm, Chem. - A Eur. J. 2016, 22, 14513-14517. b) S. Dabral, M. Turberg, A. Wanninger, C. Bolm, J. G. Hernández, Molecules 2017, 22, 146 